\title{
CREATING SAFE AND COMPETITIVE CONDITIONS FOR THE PROVISION OF RAIL TRANSPORT SERVICES
}

doi: $\quad 10.2478 /$ czoto-2019-0083

Date of submission of the article to the Editor: 06/11/2018

Date of acceptance of the article by the Editor: 22/01/2019

Renata Stasiak-Betlejewska ${ }^{1}$ - orcid id: 0000-0001-8713-237X

Ádám Török ${ }^{2}$ - orcid id: 0000-0001-6727-1540

${ }^{1}$ Czestochowa University of Technology, Poland, renata.stasiak-betlejewska@wz.pcz.pl

${ }^{2}$ Budapest University of Technology and Economics, Hungary

Abstract: Safety is a key and necessary condition for the sustainable development of the railway industry. Every entity operating in the railway area should maintain and increase the level of security as part of its operations. The subject of the analysis of data on the rail transport safety in European countries and content of the safety culture program implemented in Poland, whose main objective is to implement safety culture principles in the railway transport and to encourage all companies operating in the railway industry to improve the rail transport safety as the key condition for the sustainable development of railway industry. Paper contains results of the analysis of the European rail transport safety level in the context of the objectives set for Poland indicated by the European Union (CSI value) as improvement areas.

Keywords: railway, transport, safety, improvement

\section{INTRODUCTION}

Safety of a railway system is dependent on the balance of following three elements: "man - machine - environment". Neglecting one of the elements may cause a system imbalance as result of negative externality and thus interrupt the operation execution. The goal of optimization of ergatic systems (man machine systems) is to ensure wellbeing of humans and prevent any injuries caused by accidents. Safety of a railway system is characterized by three basic components. These are safety indicators, safety goals and safety method (Čičmancová, 2013).

Transport is the key area of the economy of the European Union what is strictly connected with sustainable development conditioned by appropriate communication links between the Member States, enabling their growth and prosperity (Gaal 2015; Kadłubek 2015; Grabara and Kot 2009). Rail transport may help to achieve essential policy objectives such as tackling climate change, fighting congestion, creating economic growth, contributing to there-industrialisation on the European continent, and providing mobility to citizens of all ages and social backgrounds (The European Union Agency for Railways, 2016). The expansion of high-speed passenger rail service is often argued as a potentially effective, lower-carbon substitute for intercity 
air travel. Previous studies on the impact of high-speed rail on air travel in Europe and Asia have primarily examined the impact of travel time and price on market share for a specific city pair. There has been little focus on the extent to which high-speed rail (HSR) has reduced total short-haul air travel demand (versus market share), or on the potential impacts of high-speed rail on system-wide air travel demand (Clewlowa et. al., 2014).

Railway is the safest form of land transport. The sense of security, comfort of travel, the ever richer transport offer and the reduction of travel time contribute to the continuous growth of interest in train travel.

Whereas transport safety research has long and established traditions, the pivotal public task of integrally governing, managing and overseeing transport safety in an effective and socio-economically cost efficient manner is yet a largely uncharted area within science. Therefore, it should not be taken for granted that all public resources are allocated where they add value the most (Mononen and Leviäkangas, 2016; Robinson and Ajay Kapoor, 2009).

One of the improvement of railway transport services possibilities is a liberalization through implementation of the adopted EU legislation. In addition to liberalization, the emphasis is on safety and technical uniformity. This means that Member States must restrict adoption of new national safety regulations in order to harmonize them. Another objective is the interoperability aimed at an optimal level of technical harmonization (Panák et al. 2017; Nedeliakova and Panák 2015).

Liberalization, privatization and globalization of economies have led to high level of competition in railway sectors and that transportation sector is growing at an exponential rate and various regulations and directives are particularly seen in this industry (Jupe and Funnell, 2015; Ozkan et al. 2016). One of the most clear objective of EU legislation is to allow third parties access to the network and to make competition a key lever in the revitalization of the sector to support security and interoperability (Crozet, 2016; Kurosaki and Singh, 2016). The institutional environment of rail transport has changed as a result of recent European directives, but the changes have taken different forms from one country to another (Gouvernal and Daydou, 2005).

In accordance with applicable national and European law, the entities operating in it are fully responsible for the safe operation of the railway system. This responsibility applies to infrastructure managers and railway undertakings as well as their subcontractors and suppliers. It results from the fact that the risk in the system is generated by individual entities and only by these entities can be effectively identified and controlled, among others based on uniform and mandatory tools such as the common safety method regarding risk assessment (The European Commission 2013) and a common security method for monitoring (The European Commission 2012). The railway system departs from the approach, under which most of the issues relevant from the point of view of security was regulated at the level of national legislation. A key role is played by active and responsible management of safety by individual entities with the use of appropriate management systems. However, the role of public authorities is to provide an appropriate legal framework for the functioning of enterprises in the rail transport sector, including solutions aimed at independent safety management in their operations. Public authorities are required to assess the ability of individual enterprises to comply with legal requirements and secure functioning in the rail transport sector before they enter the market, and then - 
to continuously supervise their competences to safely manage their operations. The role of state institutions implementing supervisory activities has also changed. There is a departure from detailed controls of compliance with legal or technical requirements, towards the assessment of the entities' ability to independently, comprehensively and responsibly manage security in their operations. To implement the above-mentioned goals, the Safety Management Systems implemented in the entities are used. One of their basic elements is the so-called change management. According to Commission Regulation (EU) No. 402/2013 in the event that the proposed change has an impact on security, the applicant, guided by professional judgment, decides on the significance of the change. As a result of the analysis, the change may be defined as significant or insignificant. The assessment process itself is based on the following criteria: consequences of failure, innovation used in the implementation of change, change complexity, monitoring, reversibility of change, assessment of the significance of the change, taking into account all recent changes in the assessed system that were related to safety and were not assessed as significant. Since one of the most important objective of the European Union Agency for Railways is to contribute to the further development and effective functioning of a single European railway area without frontiers, by guaranteeing a high level of railway safety and interoperability, while improving the competitive position of the railway sector, the main target of the paper is to present the railway safety level and safety culture basis in Poland that are a key condition for the sustainable railway development regarding European regulations.

The main objective of the paper is to review and evaluate level of the rail transport safety based on data collected by the European Union Agency for Railways through the Common Safety Indicators (CSIs) since 2006 introduced by the Railway Safety Directive (Directive 2004/49/EC). EU countries are legally obliged to submit these to the Agency. European countries were obliged to follow common definitions since 2010, thus only data from 2010 are fully harmonized. Eurostat publishes ERA's data through its dissemination database. This paper highlights selected elements.

\section{RAILWAY SAFETY IN POLAND REGARDING EU STATISTICS}

The object of the methodology is analysis of the rail transport safety in European countries that is based on data published by European Union Agency Railways in the form of Common Safety Indicators including data presented in Polish report on the railway traffic safety status and content of safety culture program implemented in Poland as the condition of fulfilling European requirements on rail safety.

The level of railway safety is traditionally expressed as the accident and casualty risk being a rate of the number of outcomes per exposure (The European Union Agency for Railways, 2016). Railway safety data are collected by the European Union Agency for Railways (hereafter ERA) through the Common Safety Indicators (CSIs) since 2006. The CSls are statistics collected at European level with the purpose specified in the Annex I to the Directive 2004/49/EC, which was later amended by the Commission Directive 149/2009/EC: "In order to facilitate the assessment of the achievement of the common safety targets and to provide for the monitoring of the general development of railway safety Member States shall collect information on Common Safety Indicators (CSIs) through the annual reports of the safety authorities as referred to in Article 18." (The European Commission 2004). The Common Safety Indicators (CSIs) is set of indicators allowing to measure railway safety performance 
of Member States and provides an objective evidence of the development over time within Member States. Accidents data are also used for estimating national reference values, setting common safety targets and assessing their achievement. CSI data on accident precursors provide additional information on the level of safety performance; however its value in supporting effective safety management at EU and national level is limited (The European Union Agency for Railways, 2016). According to European statistics the number of railway accidents has been declining between 2010 and 2016 (Figure 1).

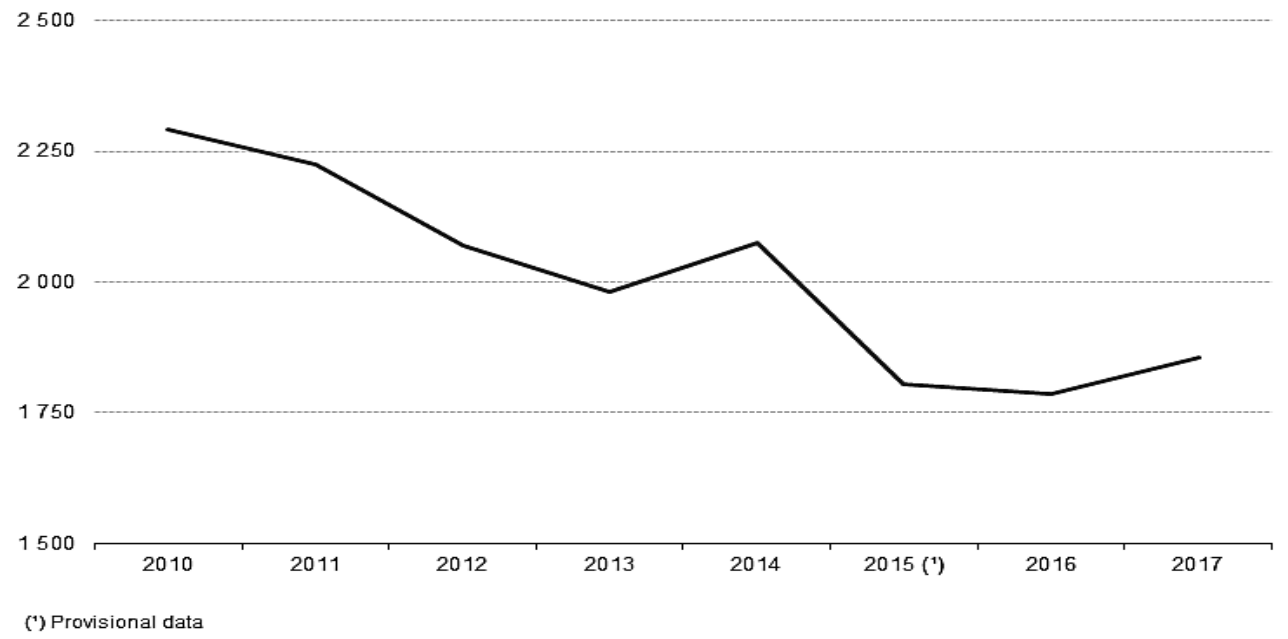

Fig. 1. Number of rail accidents in the EU 2010-2016

Source: (Eurostat, 2018).

Analyzing railway safety level at EU level, the number has been reduced by $22 \%$ since 2010 (from 2291 to 1787 accidents). In 2015, the decrease compared with the previous year was particularly marked $(-13 \%)$ and its continues in 2016 with a slight decrease of $1 \%$ compared to 2015, but not in all categories: the numbers of accidents to persons by rolling stock in motion and fires in rolling stock have increased (Eurostat 2018). In figure 2 the number of rail accidents in European countries was presented for 2010 and 2017.

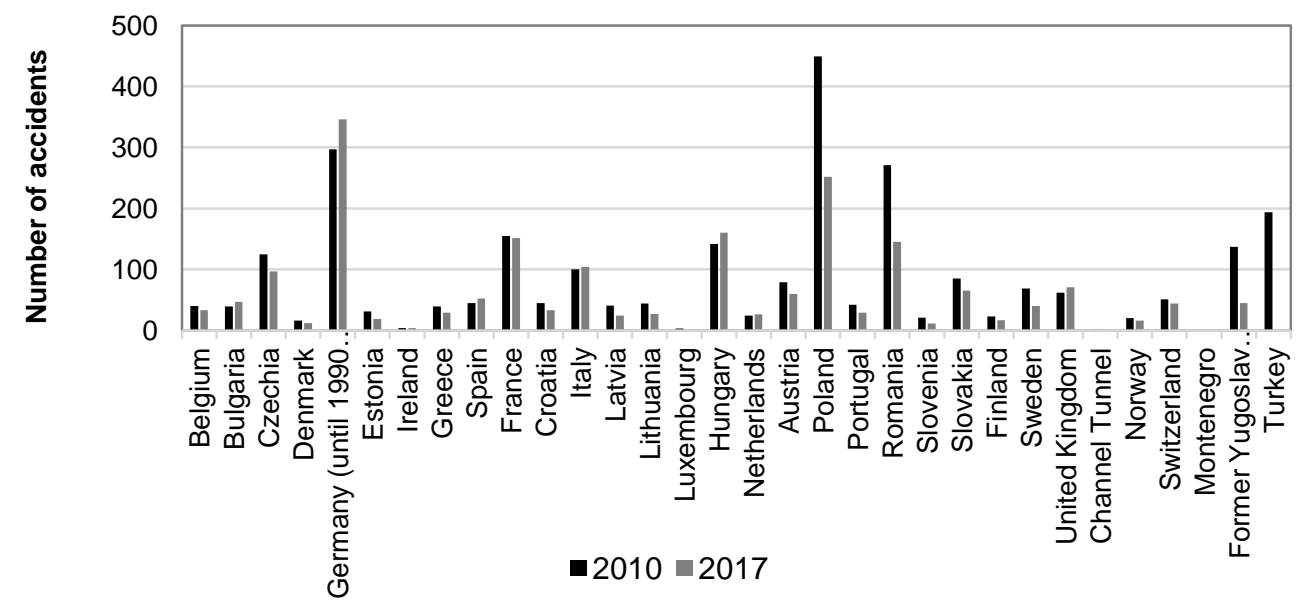

Fig. 2. Number of rail accidents in European Union countries in 2010 and 2017 Source: (Eurostat, 2018). 
According to the latest CSIs reported (2016), the raw data reveals a slight increase of fatalities and an increase of serious injuries over a reduced number of accidents. The highest number of accidents in 2016 has been noted in Poland and Germany (both countries together having a share of $32 \%$ of all accidents recorded in the EU-28 in 2016), while Hungary has noted only 162 accidents (9\% of EU railway accidents). Ireland hasn't reported any single railway accident. Statistics within CSI data shows that railway safety level in the EU-28 has registered a general improvement since 2010. Up to 2015 the number of fatalities and serious injuries was down, as was the number of significant accidents. Data confirms that trend reflects either: better or increased reporting of precursor incidents, an increase in railway safety risk or a combination of the above.

The year 2016 was the safest year in the rail transport in Poland in the last 7 years. This was the result of the efforts of many people involved in rail transport at every level of its operation - from the Ministry, in the context of financing, through certification and supervision of the President of the Rail Transport Office to the direct daily care of railway employees. In 2016 , the number of railway accidents and the number of people killed by more than $25 \%$ decreased. This should be perceived especially positively considering the increase in operational work in the past year. In the overall safety performance assessment, one cannot forget about the need for continuous work on safety improvement. Polish railway safety challenges concern several issues: improving safety in the incidents related to the transport of dangerous goods, monitoring the level of train drivers training as well as general supervision over the rail transport safety. For this reason, the decision was taken in Poland for taking special safety oversight of the transport of dangerous goods and the implementation of two innovative projects in the coming years: Monitoring Center of Machinists and ERail Safety. In 2016, the number of registered incidents increased, i.e. the category with the lowest consequences, which in previous years was strongly underestimated. In this connection, it is necessary to respond positively to the increase in the identification of this category of events as the effect of implementing a safety culture in the railway transport. In 2017, Poland recorded stabilization of the accident rate at the level of approximately 2.5 accidents per million cubic miles. While there was an increase in the incidence of rail accidents, there were fewer injured people. Their number decreased by $6.2 \%$ compared to 2016. In 2017 there was noted increase in the security culture level, what is the result of implementing the Polish declaration of safety culture in rail transport signed by 177 entities mainly related to the railway market. A manifestation of the ever-growing safety culture is the increased number of incidents and potentially dangerous situations.

Polish Railway Safety is aimed at Common Safety Targets (CSTs), that are quantitative measures of risk assessing whether the current safety levels of the railways in the Member States are at least maintained (The European Union Agency for Railways, 2016). The Common Safety Targets, in accordance with the Safety Directive, set out the minimum safety levels expressed in the acceptance criteria, which must be achieved by different parts of the railway system and by the railway system as a whole. CSTs are designated by the European Union Rail Agency on the basis of the so-called National Reference Values (NRV) for individual countries, in accordance with the procedure set out in the Commission Decision of 5 June 2009 concerning the adoption of a common safety method for assessing whether the safety requirements referred to in Directive 2004/49/EC of the European Parliament and of 
the Council. Member States are required to continuously monitor the safety level of their rail systems, including monitoring the achievement of common safety objectives (CSTs), quantified and qualitatively defined.

In 2017, the level of common safety objectives in quantitative and qualitative terms was achieved for five individual risk groups including passengers, employees, users of journeys, unauthorized persons in the railway area and the so-called "Other people" and the level of common risk. In 2017, none of the indicators calculated for specified risk groups based on statistical data included in the form of common safety indicators (CSI), exceeded the acceptable level of risk and reference values (NRV) established for Poland. The lowest values of the indicator, indicating an increasing level of safety, were achieved for the risk group concerning other people: $7.1 \%$. In the passenger risk group, the values achieved are higher than in 2016 and amount to $15.9 \%$ for CST 1.1 and $17.4 \%$ for CST 1.2 , respectively. The value of the risk indicator for users of journeys is $31.2 \%$, which is a decrease by 13.7 percentage points compared to the previous year. It is also the highest of the CST values achieved.

The application of the "just culture" principle in the Polish Railway entity's activity as well as in the relations between the entity - the Railway Transport Office reveals full trust and transparency in the exchange of information on factors affecting safety. Thanks to such a procedure, it is possible to more precisely determine the causes and identify threats in rail transport. In 2016, again, good railway safety results in Poland were noted in the context of the objectives set by the European Union in terms of CST values. The average CST value for Poland is around 33\% of the acceptable level.

Particularly optimistic results were recorded in the area of passenger risk - about $16 \%$ of the acceptable level. In this category, the level of risk registered in Poland is one of the lowest in the entire European Union. A cross-sectional report by the Supreme Audit Office indicates a number of areas for railways that need to be improved on the railways. However, the activities of the President of UTK to improve the safety of the railway system were assessed positively. These effects were achieved at a special time for Polish rail transport. The uniqueness of this period lies in the number of investments, which in 2017 was record-high. However, the side effect is the disruption of the normal operating conditions of the railway system. This is a source of new threats, but after the completion of the investment, the market will be ready to provide services at an unprecedented level in our country - both in terms of their quality and safety.

\section{CONCLUSION}

Safety is a key and necessary condition for the sustainable development of the railway industry. Every entity operating in the railway area should maintain and increase the level of security as part of its operations. A security culture can be defined as a system that includes attitudes of a specific group in terms of risk, security and threats, indicating values that are considered to be key in a given area. Safety culture is the basic premise of an efficiently operating railway system, and safety management systems based on security culture are indispensable elements in all railway organizations in order to maintain and increase the level of safety. A correctly understood security culture is based on a high level of trust and respect between employees and management, which is why it must be created and supported by senior management. 


\section{ACKNOWLEDGEMENTS}

This paper was supported by the János Bolyai Research Scholarship of the Hungarian Academy of Sciences.

\section{REFERENCES}

Clewlowa, R.R., Sussman, J.M., Balakrishnan, H., 2014. The impact of high-speed rail and low-cost carriers on European air passenger traffic. Transport Policy, 33 (5), 136-143, DOI: 10.1016/j.tranpol.2014.01.015

Crozet, P.Y., 2016. Introducing competition in the European rail sector. Insights for a holistic regulatory assessment. Draft Discussion Paper prepared for the Roundtable on Assessing regulatory changes in the transport sector, Stockholm, 2.

Čičmancová, S., 2013. Safety of railway system, Perner's Contacts, 8, 2.

Gaal, G., Horváth, E., Török, Ádám and Csete, M., 2015. Analysis of Public Transport Performance in Budapest, Hungary. Periodica Polytechnica Social and Management Sciences, 23, 1, 68-72, DOI: 10.3311/PPso.7724.

Gouvernal, E., Daydou, J., 2005. Container Railfreight Services in North-west Europe: Diversity of Organizational Forms in a Liberalizing Environment. Transport Reviews, 25(5), 557-571, DOI: 10.1080/01441640500072127.

Grabara, J., Kot, S., 2009. Theoretical frames for designing reverse logistics processes. Review of General Management, 1, 55-61.

Jupe, R., Funnell, W., 2015. Neoliberalism, consultants and the privatisation of public policy formulation: The case of Britain's rail industry. Critical Perspectives on Accounting, 29, 65-85, DOI: 10.1016/j.cpa.2015.02.001.

Kadłubek, M., 2015. Examples of Sustainable Development in the Area of Transport. Procedia Economics and Finance, 27, 494-500, DOI: 10.1016/S22125671(15)01026-6.

Kurosaki, F., Singh, M., 2016. Comparison of three models for introducing competition in rail freight transport. Transportation Research Procedia, 14, 2820-2829, DOI: 10.1016/j.trpro.2016.05.348.

Mononen, P., Leviäkangas, P., 2016. Transport safety agency's success indicators How well does a performance management system perform? Transport Policy, Elsevier, 45 (C), 230-239, DOI: 10.1016/j.tranpol.2015.03.015.

Nedeliakova, E., Panák, M., 2015. New Trends in Process-oriented Quality Management. Procedia Economics and Finance, 34, 172-179, DOI: 10.1016/S2212-5671(15)01616-0.

Ozkan, T., Yanginlar, G., Kalayci, S., 2016. Railway Transport Liberalization: A Case Study of Various Countries in the World. Journal of Management and Sustainability, 6, 4, 140-148, DOI: 10.5539/jms.v6n4p140.

Panák, M., Nedeliaková, E., Abramović, B., Šipuš, D. 2017. Synergies of the Liberalization of the Railway Transport Market. MATEC Web of Conferences 134:00045, DOI: 10.1051/matecconf/201713400045.

Robinson, M., Kapoor, A., 2009. Fatigue in railway infrastructure. Woodhead Publishing Limited, Abington Hall, Granta Park, Great Abington, Cambridge CB21 6AH, UK, 97.

The European Commission, 2013. Commission implementing regulation (EU) No 402/2013 of 30 April 2013 on the common safety method for risk evaluation and assessment and repealing Regulation (EC) No 352/2009. Official Journal of the European Union, https://eur-lex.europa.eu. 
The European Commission, 2012. Commission regulation (EU) No 1078/2012 of 16 November 2012 on a common safety method for monitoring to be applied by railway undertakings, infrastructure managers after receiving a safety certificate or safety authorization and by entities in charge of maintenance. Official Journal of the European Union, https://eur-lex.europa.eu.

The European Commission, 2004. Directive 2004/49/EC of the European Parliament and of the Council of 29 April 2004 on safety on the Community's railways and amending Council Directive 95/18/EC on the licensing of railway undertakings and Directive 2001/14/EC on the allocation of railway infrastructure capacity and the levying of charges for the use of railway infrastructure and safety certification (Railway Safety Directive), Official Journal of the European Union, https://eurlex.europa.eu.

The European Union Agency for Railways, 2016. Railway Safety Performance in the European Union. Belgium, DOI: 10.2821/171211.

The Office of Rail Transport in Poland, 2017. Report on the railway traffic safety status in 2017, Warsaw 2018, 115-117. 